\title{
Epigenetic Profiling of H3K4Me3 Reveals Herbal Medicine Jinfukang-Induced Epigenetic Alteration Is Involved in Anti-Lung Cancer Activity
}

\author{
Jun Lu, ${ }^{1}$ Xiaoli Zhang, ${ }^{1}$ Tingting Shen,, Chao Ma, ${ }^{2}$ Jun Wu, ${ }^{1}$ Hualei Kong, ${ }^{1}$ Jing Tian, \\ Zhifeng Shao, ${ }^{1}$ Xiaodong Zhao, ${ }^{1,2}$ and Ling $\mathrm{Xu}^{2,4}$ \\ ${ }^{1}$ Shanghai Center for Systems Biomedicine, School of Biomedical Engineering, State Key Laboratory on Oncogene and \\ Bio-ID Center, Shanghai Jiao Tong University, 800 Dongchuan Road, Shanghai 200240, China \\ ${ }^{2}$ Tumor Institute of Traditional Chinese Medicine, Longhua Hospital, Shanghai University of Traditional Chinese Medicine, \\ 725 South Wanping Road, Shanghai 200032, China \\ ${ }^{3}$ College of Life Science, Northwest University, 229 Taibai Road, Xian 710069, China \\ ${ }^{4}$ Department of Oncology, Yueyang Hospital of Integrated Traditional Chinese and Western Medicine, \\ Shanghai University of Traditional Chinese Medicine, 110 Ganhe Road, Shanghai 200437, China \\ Correspondence should be addressed to Ling Xu; xulq67@aliyun.com
}

Received 2 November 2015; Revised 3 February 2016; Accepted 7 February 2016

Academic Editor: Ching-Liang Hsieh

Copyright (C) 2016 Jun Lu et al. This is an open access article distributed under the Creative Commons Attribution License, which permits unrestricted use, distribution, and reproduction in any medium, provided the original work is properly cited.

\begin{abstract}
Traditional Chinese medicine Jinfukang (JFK) has been clinically used for treating lung cancer. To examine whether epigenetic modifications are involved in its anticancer activity, we performed a global profiling analysis of H3K4Me3, an epigenomic marker associated with active gene expression, in JFK-treated lung cancer cells. We identified 11,670 genes with significantly altered status of H3K4Me3 modification following JFK treatment $(P<0.05)$. Gene Ontology analysis indicates that these genes are involved in tumor-related pathways, including pathway in cancer, basal cell carcinoma, apoptosis, induction of programmed cell death, regulation of transcription (DNA-templated), intracellular signal transduction, and regulation of peptidase activity. In particular, we found that the levels of H3K4Me3 at the promoters of SUSD2, CCND2, BCL2A1, and TMEM158 are significantly altered in A549, NCI-H1975, NCI-H1650, and NCI-H2228 cells, when treated with JFK. Collectively, these findings provide the first evidence that the anticancer activity of JFK involves modulation of histone modification at many cancer-related gene loci.
\end{abstract}

\section{Introduction}

Chromatin is the macromolecular complex of DNA and histone proteins that provides the scaffold for packaging the eukaryotic genome $[1,2]$. Histones $\mathrm{H} 2 \mathrm{~A}, \mathrm{H} 2 \mathrm{~B}, \mathrm{H} 3$, and $\mathrm{H} 4$ are the basic components of nucleosomes, which form the fundamental unit of chromatin [3,4]. Chemical modifications to the histones alter chromatin structure and regulate gene expression by altering noncovalent interactions within and between nucleosomes [2, 5]. H3K4Me3 is an active histone modification which is positively associated with gene expression $[3,6]$. Previous studies have shown that the levels of H3K4Me3 modification are closely associated with the development, treatment, and diagnosis of disease [7-9]. Chromatin immunoprecipitation followed by sequencing (ChIP-seq) has been developed to systematically characterize the contribution of epigenetic regulation in various biological processes via genome-wide profiling of various chemical modifications of histone proteins and genomic DNA methylation [10].

Lung cancer has become the leading cause of cancerrelated deaths worldwide [11]. Overall, only $16.8 \%$ of patients with lung cancer survive five years after their first definite diagnosis, mainly as a consequence of uncontrollable cell proliferation or tumor metastasis [12, 13]. Although various therapeutic interventions, including surgery, chemotherapy, and radiotherapy, have been developed to prolong the survival time of patients, drug side effects, pain, and emaciation 
are still significant problems for tumor sufferers and their physicians $[14,15]$.

Traditional Chinese medicine (TCM) has been employed in the treatment of many diseases for several thousand years and still plays an important role in public health in present day [16]. Jinfukang (JFK), a TCM formula, has been clinically used for treating lung cancer patients for more than ten years, and its curative effects have been reported to be promising [14, 17-19]. However, although the clinical effects of JFK are known [17], its antitumor mechanism remains unclear. In previous study, researchers demonstrated that JFK modulates the expression of genes which are involved in the cell cycle and apoptosis [18]. In the present study, we examined the pattern with $\mathrm{H} 3 \mathrm{~K} 4 \mathrm{Me} 3$ pattern modulated by JFK in A549 cells and the implication in its antitumor activity of JFK.

\section{Materials and Methods}

2.1. Animals and Treatments. All animals received humane care during the study, under a protocol that was in accordance with institutional guidelines. Sprague-Dawley rats were obtained from Shanghai SLAC Laboratory Animal Co., Ltd. All rats were fed laboratory rat-fodder and water, ad libitum, and were maintained at $22 \pm 1^{\circ} \mathrm{C}$ and lighting was set for $12 \mathrm{~h}$ on, $12 \mathrm{~h}$ off. In this experiment, 20 rats were divided into two groups including control and JFK. Rats were administrated orally $1 \mathrm{~mL}$ saline for control group and $4 \mathrm{~g} \mathrm{Kg}^{-1}$ body weight JFK (volume: $1 \mathrm{~mL}$ ) for JFK group, respectively, three times a day for 15 consecutive days.

2.2. JFK Drug Serum Preparation. The procedures of drug serum preparation were performed according to a previous study [20]. Briefly, two hours after the last administration, all blood samples were collected by abdominal aortic method under the state of anesthesia using pentobarbital sodium. Each rat was sacrificed by cervical dislocation. The concretionary blood was centrifuged at 1,500 $\mathrm{g}$ for $15 \mathrm{~min}$, and then the JFK drug serum was collected and stored at $-80^{\circ} \mathrm{C}$.

2.3. Cells and Cell Culture. The human lung cancer cell lines A549, NCI-H1975, NCI-H1650, and NCI-H2228 were obtained from the Shanghai Institute of Biochemistry and Cell Biology. Cells were cultured in RPMI-1640 Medium (Gibco, USA) and maintained at $37^{\circ} \mathrm{C}$ in a humidified atmosphere of $5 \% \mathrm{CO}_{2}$. Growth media were supplemented with $10 \%$ fetal bovine serum (FBS) (Gibco, USA) and penicillin/streptomycin (Life Technologies, Inc., USA) final concentration is $100 \mathrm{U} / \mathrm{mL}$. The cells were subcultured when they reached approximately $90 \%$ confluence using a $0.25 \%$ trypsin solution. For observation of JFK-induced cell alteration, 10\% control serum and JFK drug serum were supplemented to growth media for replacing $10 \%$ FBS, respectively.

2.4. Cell Viability Analysis. Cells were cultured in 96-well plates overnight and incubated with indicated serums for $12 \mathrm{~h}$, $24 \mathrm{~h}, 48 \mathrm{~h}, 72 \mathrm{~h}, 96 \mathrm{~h}$, and $120 \mathrm{~h}$, respectively. Cellular viability was measured by Cell Counting Kit 8 (CCK8) (Dojindo, Japan). In brief, the cell proliferation reagent WST-8 $(10 \mu \mathrm{L})$ was added to each well and cells were incubated for $2 \mathrm{~h}$ at $37^{\circ} \mathrm{C}$. Viable cell numbers were estimated by measuring the optical density (OD) at $450 \mathrm{~nm}$. Absorbance of control group was set as $100 \%$ viability, and absorbance of cell-free wells containing medium was set as zero.

2.5. DAPI Staining. A549 cells were fixed in $4 \%$ paraformaldehyde and then stained with DAPI (Sigma, USA) and observed using Confocal Laser Scanning Microscopy (CLSM) (Nikon, Japan). Cells were viewed to be damaged if the dissolution, condensation, or fragmentation of nuclei was observed.

2.6. PI Staining. A549 cells were fixed, stained with PI (Sigma, USA), and observed using fluorescence microscopy (Nikon, Japan). Pictures were obtained through fluorescence microscopy at the excitation wavelength of $536 \mathrm{~nm}$. Cells were designated as being dead if they had highly red color and nondead if the staining was slight or none.

2.7. Cell Apoptosis Analysis. Determination of phosphatidylserine (PS) and membrane integrity was performed by Annexin V-FITC/PI Apoptosis kit (Zoman, China). In brief, A549, NCI-H1975, NCI-H1650, and NCI-H2228 cells were harvested by trypsin (no EDTA) and washed twice with PBS, then stained with Annexin V-FITC/PI, and analyzed by flow cytometry (BD LSRFortessa, USA).

2.8. Chromatin Immunoprecipitation (ChIP) Assay. ChIP assay was performed as previously described [10]. In brief, $3.5 \times 10^{6}$ cells were rinsed with PBS, cross-linked with $1 \%$ formaldehyde and quenched with $2.5 \mathrm{M}$ glycine (Sigma, USA), and then harvested in a $1.5 \mathrm{~mL}$ tube. $100 \mathrm{bp}$ to $300 \mathrm{bp}$ chromatin fragments were obtained after sonication with indicated condition. $1 \%$ total fragmented DNA was transferred to a new tube set as input. Immunoprecipitated DNA fragments were captured by $\mathrm{H} 3 \mathrm{~K} 4 \mathrm{Me} 3$ antibody (Abcom, USA), following quantification by Picogreen measurement kit. Primers of MYC and EGFR were designed for detecting whether the immunoprecipitated DNAs were enriched and qualified for library procedure. Primer sequences were showed in Table 1.

2.9. Library Preparation and ChIP-Seq. For library, 40 $50 \mathrm{ng}$ immunoprecipitated DNAs and input DNAs were end-repaired and ligated adapters to the DNA fragments using NEBNext Ultra End-Repair/dA-Tailing Module and NEBNext Ultra Ligation Module (NEB, USA), respectively. DNA size selection was performed using 2\% Agarose Gel; then 200 500 bp DNA fragments were excised and purified using Qiagen Gel Extraction Kit (Qiagen, Germany). Each sample was amplified for 14 cycles in a DNA thermal cycler using Q5 High-Fidelity DNA Polymerase (NEB, USA) and corresponding PCR Master Mix. Lastly, the PCR products were quantified using Nanodrop and performed standard single end sequencing with $50 \mathrm{bp}$ reads using Illumina Hiseq 2000 (Illumina, USA). The raw sequencing data of this study 
TABle 1: Primer sequences for ChIP-qPCR and RT-qPCR.

\begin{tabular}{|c|c|c|c|c|}
\hline Type & Gene & GenBank & Forward $\left(5^{\prime}-3^{\prime}\right)$ & Reverse $\left(5^{\prime}-3^{\prime}\right)$ \\
\hline \multirow{12}{*}{ ChIP-qPCR } & $M Y C$ & [NM_002467] & CATTCCTGCGCTATTGACAC & AAAAACCATTCCCGTTTTCC \\
\hline & EGFR & [NM_005228] & AGGGAAGCTGAGGAAGGAAC & CGGCTTCAGTTTGAGACCTG \\
\hline & SUSD2 & [NM_019601] & AGCCTCTGTCCATCTGTCAG & TTCTTCССАТСACСССТAGC \\
\hline & $P T N$ & [NM_002825] & GAGCCCTCCGAGAAATCGTA & CAACAAAGGCAGACTGAGCG \\
\hline & GLIS2 & [NM_032575] & GGTGCCAAAGGATGTTGCTT & CACAAGGGCAGGATGGTTTG \\
\hline & CCND2 & [NM_0201759] & CGCGTTCCCTAGTTTCTGTC & GAAACTTGAAGGGGTGAGCG \\
\hline & TM4SF4 & [NM_004617] & GAGGCAGTGAGGAGCTTTTG & AAAGCAAGGGGAATGAGGGT \\
\hline & $B C L 2 A 1$ & [NM_004049] & TATCCACATCCGGGGCAATT & ACGGCATCATTAACTGGGGA \\
\hline & IL31RA & [NM_139017] & GCAGAGTGTCAGCTTGTTCC & TTGCGGACATTCACAGACAC \\
\hline & WISP2 & [NM_003881] & CTTGGGTCAGCTCTGCAAAG & CTGCTGTAGTTGTGAAGCCC \\
\hline & TNFAIP6 & [NM_007115] & TGCTTCATGGACTCTGAGCT & TTTCTGTACTGCAAGCTGGC \\
\hline & TMEM158 & [NM_015444] & TTTGGAAAGGCTGGGAAACG & GGGAGAGGGCACGATTAGAA \\
\hline \multirow{4}{*}{ RT-qPCR } & SUSD2 & [NM_019601] & CATGAAGCCAGCCCTCCT & GTCGGGTGGCAGGAACAT \\
\hline & CCND2 & [NM_0201759] & CTCCTACTTCAAGTGCGTGC & TCGCACTTCTGTTCCTCACA \\
\hline & $B C L 2 A 1$ & [NM_004049] & AGGTGTGTGATTGTGCCATT & AATTGCCCCGGATGTGGATA \\
\hline & TMEM158 & [NM_015444] & GCCTAGACTTCAGCCTGGAG & ACCAGGGTCATGAAGCAGG \\
\hline
\end{tabular}

are available in the EMBL database under accession number E-MTAB-3992: http://www.ebi.ac.uk/arrayexpress/.

2.10. Bioinformatic Analysis. Raw data were extracted and initially analyzed by Illumina software. We used FastQC software to detect data quality. After prefiltering the raw data by removing sequenced adapters and low quality reads, the sequence tags were aligned to human genome (NCBI/hg19) with Bowtie alignment tool [21]. After being filtered, at least 12 million unique reads per sample were used for peak detection. Peak detection was performed using the MACS program with a two-sample analysis where sequenced input (1\%) was used as negative control [22]. Due to the differences in the number of reads between experimental data and input DNA data, a random subselection was applied to the larger data set for normalization. The statistics of RNA-seq data sets were shown in Table 2.

For identifying qualified peak regions, experimental data and input DNA data were consolidated in a window size of $100 \mathrm{bp}$ and $P$ value $<0.05$. To compare JFK-treated versus control H3K4Me3 ChIP data sets, the two lists of peaks were matched based on overlapped genome positions. Matched peak regions were annotated using UCSC annotation database and genes with qualified peaks within 2,000 bp of the Transcriptional Start Sites (TSSs) were identified. Fold change was also calculated for each matched peak region comparing JFK-treated versus control H3K4Me3 peaks.

The Database for Annotation, Visualization and Integrated Discovery (DAVID) bioinformatics resource was used to annotate gene functions and pathways [23]. Briefly, Gene Ontology (GO) analysis [24] and Kyoto Encyclopedia of Genes and Genomes (KEGG) pathways analysis [25] were performed by uploading differential gene list to DAVID Bioinformatics Resources 6.7. Besides, network construction was performed using Reduce Visualize Gene Ontology (http://revigo.irb.hr/), and then network graph was modified using Cytoscape software (version 3.2.1).
2.11. ChIP-qPCR Validation. Immunoprecipitated DNAs from control and JFK samples were obtained by ChIP assays which are described as previously mentioned. For validation of target genes $\mathrm{H} 3 \mathrm{~K} 4 \mathrm{Me} 3$ modification fold change, all target gene primers were designed using Primer3 web (version 4.0.0). All primer sequences are showed in Table 1.

2.12. Quantification of $m R N A$ Level. Transcription level of genes of interest was evaluated using quantitative real-time PCR (RT-qPCR) with SYBR Green PCR Master Mix (Bestar, Germany). RT-qPCR was performed according to standard procedure. All primer sequences used for RT-qPCR were shown in Table 1.

2.13. Statistical Analysis. Data are presented as the mean $\pm \mathrm{SD}$. The differences between the groups were examined using the standard one-way ANOVA. SPSS for Windows 14.0 software package was used. Differences were considered significant at $P<0.05$.

\section{Results}

3.1. A549 Cell Viability and Cell Nucleus Morphology Are Changed after Incubation with JFK. The survival rate and changes to the nuclear morphology of A549 cells were monitored via a multimode reader and optical microscopy. We observed that cell viability decreases significantly after $24 \mathrm{~h}$ incubation with JFK drug serums obtained from day 7 and day 14 (Figure 1(a)). In addition, time-dependent assays suggest that cell viability reduces significantly when A549 cells are exposed to the JFK serum from day 14 for incubation times longer than $24 \mathrm{~h}$ (Figure 1(b)). Thus, we chose a $48 \mathrm{~h}$ incubation time with JFK for all future experiments. Interestingly, nuclear staining with DAPI revealed alterations to the nuclear morphology in response to JFK. As shown in Figures 1(c) and 1(d), after the JFK treatment for $48 \mathrm{~h}$, many 
TABLE 2: The statistics of ChIP-seq data sets.

\begin{tabular}{lcccc}
\hline & Total reads & Unique mapping reads & Mapping rate & Sequencing quality (Q30) \\
\hline Control input & 36251128 & 31414275 & $86 \%$ & 97.49 \\
Control & 26353782 & 20332230 & $77 \%$ & 97.13 \\
JFK input & 17592377 & 10755542 & $61 \%$ & 96.1 \\
JFK & 16435835 & 12904340 & $79 \%$ & 97.22 \\
\hline
\end{tabular}

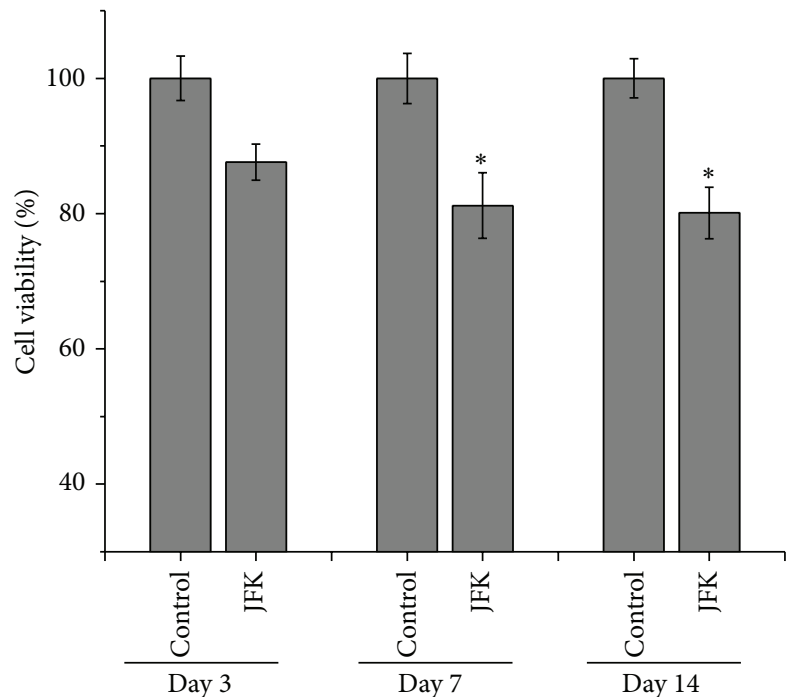

(a)

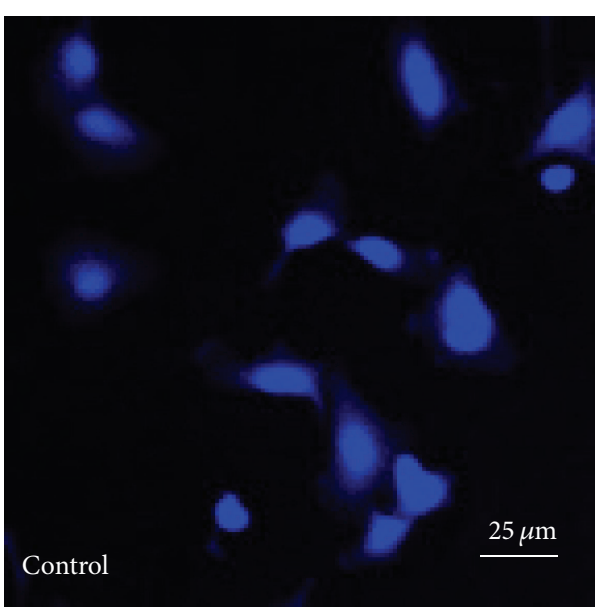

(c)

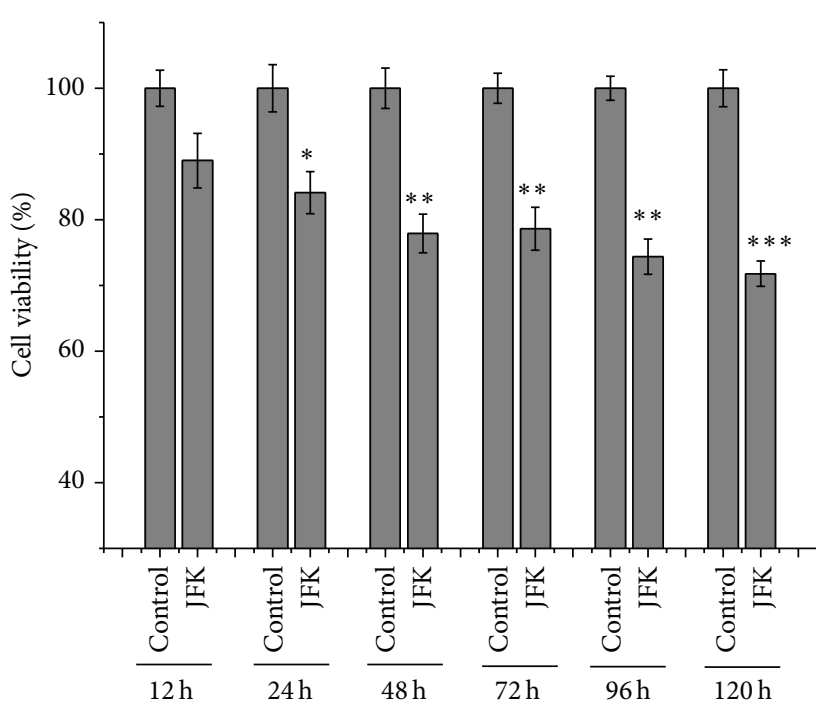

(b)

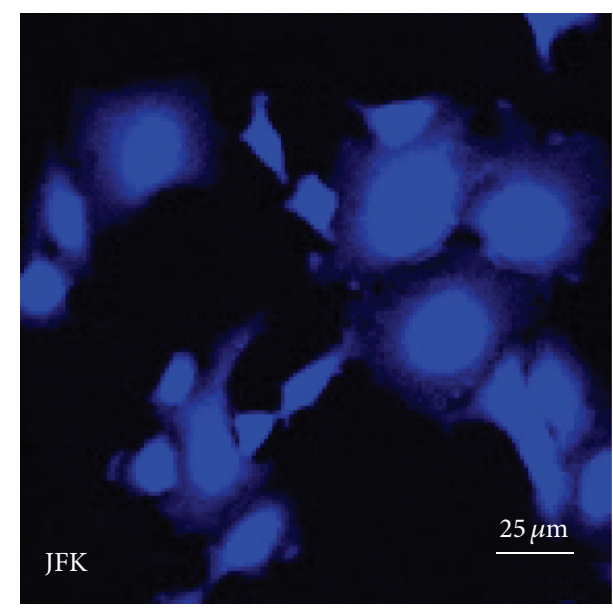

(d)

FIGURE 1: Treatment with JFK induces proliferation inhibition and nuclear morphology alteration in A549 cells. (a) A549 cells were treated with JFK drug serums from day 3 , day 7, and day 14 , respectively $\left(n=3,{ }^{*} P<0.05\right)$. (b) A549 cells were treated with JFK drug serum from day 14 for $12 \mathrm{~h}, 24 \mathrm{~h}, 48 \mathrm{~h}, 72 \mathrm{~h}, 96 \mathrm{~h}$, and $120 \mathrm{~h}$, respectively $\left(n=3,{ }^{*} P<0.05,{ }^{* *} P<0.01\right.$, and $\left.{ }^{* * *} P<0.001\right)$. (c, d) A549 cells were stained with DAPI for detecting nucleus changes using CLSM. Scale bar: $25 \mu \mathrm{m}$.

nuclei were markedly larger compared to those in the control, indicating that these cells are in a state of abnormality.

3.2. Proapoptotic Effects of JFK on A549 Cells. To further understand the effects of JFK on A549 cells, we examined the number of apoptotic cells by staining with PI and using fluorescence microscopy. As shown in Figure 2(a), cells colored red, indicative of apoptosis, are found following treatment with JFK, suggesting that JFK could induce apoptosis in these cells. Flow cytometric analysis also showed a significant increase in JFK-induced apoptosis compared to a vehicle treatment control (Figure 2(b)). In particular, the total apoptosis rate calculated as Annexin and PI positive cells and the early apoptosis rate calculated as Annexin positive cells, respectively, by flow cytometry were significantly increased in 

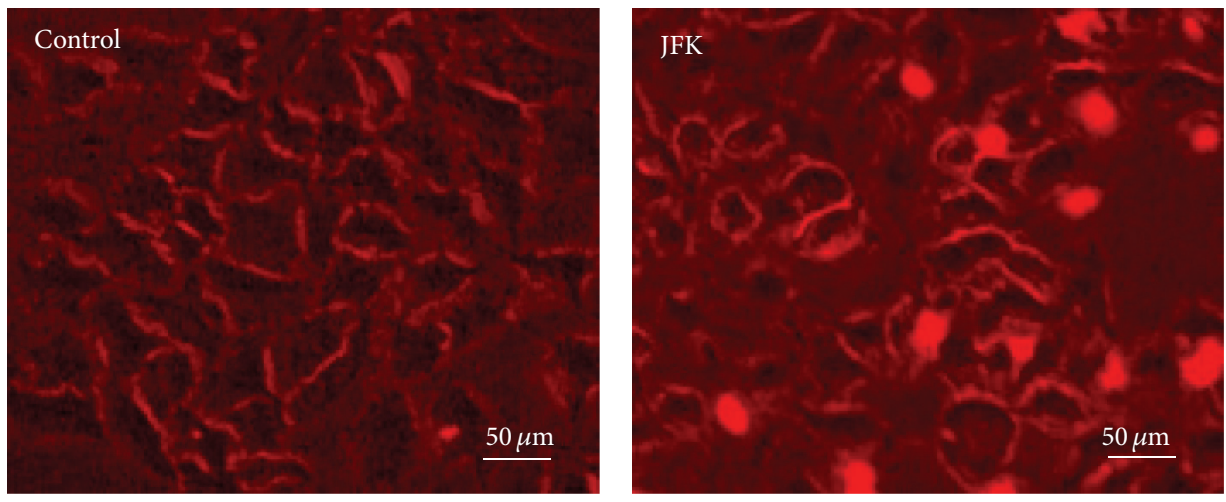

(a)
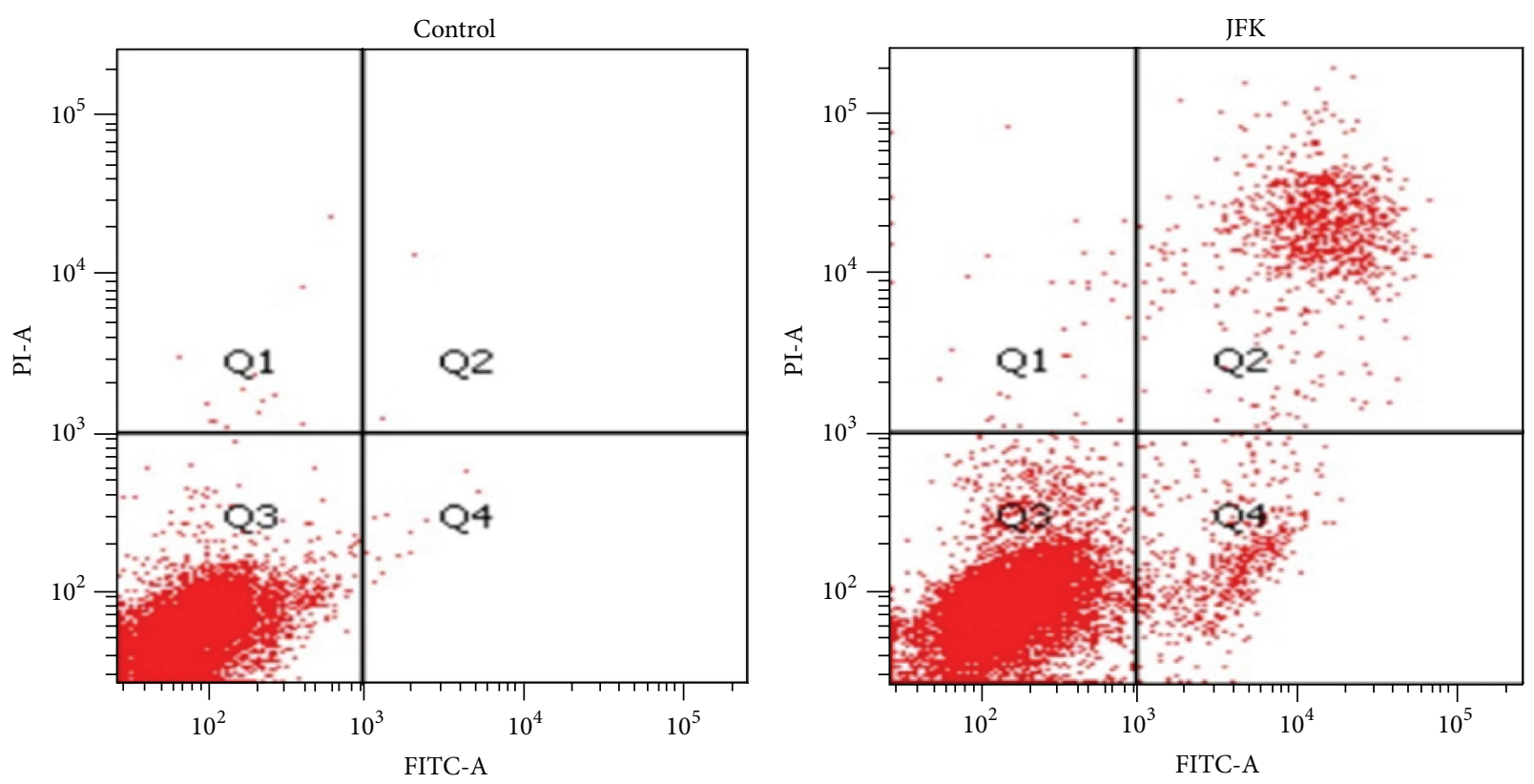

(b)

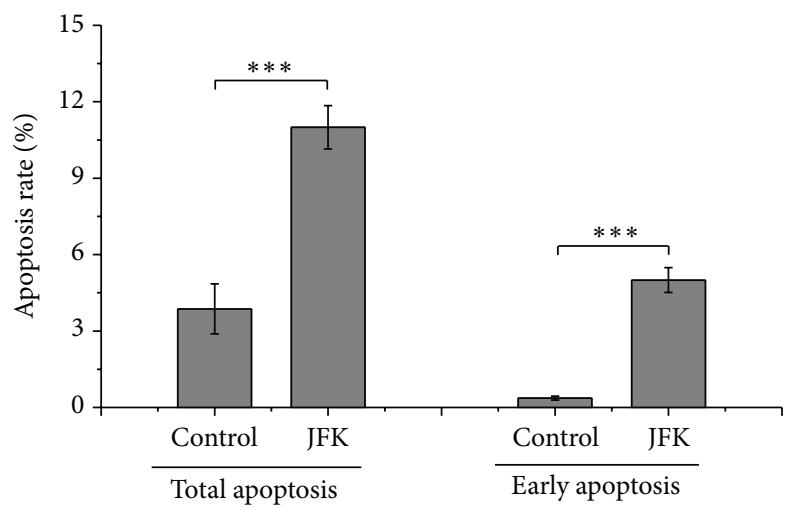

(c)

FIGURE 2: Treatment with JFK induces cell death and apoptosis in A549 cells. (a) A549 cells were stained with PI for detecting deathbed cells using fluorescence microscope. Scale bar: $50 \mu \mathrm{m}$. (b) A549 cells were treated with JFK, and the apoptotic progression was determined by flow cytometry. (c) Total apoptosis and early apoptosis ratios were analyzed based on results of flow cytometry $\left(n=3,{ }^{* * *} P<0.001\right)$. 
TABLE 3: GO analysis of top 2000 downregulated genes and upregulated genes, respectively.

\begin{tabular}{|c|c|c|c|}
\hline Category & Item & Count & $P$ value \\
\hline \multicolumn{4}{|c|}{ Downregulated } \\
\hline GO:0006811 & Ion transport & 112 & $2.02 E-05$ \\
\hline GO:0016055 & Wnt receptor signaling pathway & 29 & $8.47 E-05$ \\
\hline GO:0051347 & Positive regulation of transferase activity & 43 & $1.66 E-04$ \\
\hline GO:0006350 & Transcription & 255 & $1.67 E-04$ \\
\hline GO:0007242 & Intracellular signaling cascade & 162 & $2.22 E-04$ \\
\hline GO:0051338 & Regulation of transferase activity & 59 & $2.88 E-04$ \\
\hline GO:0033674 & Positive regulation of kinase activity & 41 & $2.95 E-04$ \\
\hline GO:0043549 & Regulation of kinase activity & 57 & $3.12 E-04$ \\
\hline GO:0045859 & Regulation of protein kinase activity & 55 & $4.21 E-04$ \\
\hline GO:0045860 & Positive regulation of protein kinase activity & 39 & $5.70 E-04$ \\
\hline \multicolumn{4}{|c|}{ Upregulated } \\
\hline GO:0012501 & Programmed cell death & 65 & $1.94 E-06$ \\
\hline GO:0006917 & Induction of apoptosis & 39 & $3.86 E-06$ \\
\hline GO:0050870 & Positive regulation of T-cell activation & 14 & $4.85 E-05$ \\
\hline GO:0006915 & Apoptosis & 65 & $4.97 E-04$ \\
\hline GO:0006631 & Fatty acid metabolic process & 27 & $5.34 E-04$ \\
\hline GO:0012502 & Induction of programmed cell death & 39 & $5.74 E-04$ \\
\hline GO:0031348 & Negative regulation of defense response & 9 & $8.36 E-04$ \\
\hline GO:0052547 & Regulation of peptidase activity & 15 & $1.15 E-03$ \\
\hline GO:0006793 & Phosphorus metabolic process & 97 & $1.38 E-03$ \\
\hline GO:0006796 & Phosphate metabolic process & 97 & $1.72 E-03$ \\
\hline
\end{tabular}

A549 cells after JFK treatment, compared to those in vehicle treated A549 cells (Figure 2(c)).

3.3. JFK Induces an Alteration in the H3K4Me3 Pattern in A549 Cells. Previous studies have reported that the level of $\mathrm{H} 3 \mathrm{~K} 4 \mathrm{Me} 3$ modification in TSSs is linked to transcriptional activation $[3,6]$. To examine the alteration of H3K4Me3 modification upon exposing A549 cells to JFK, we performed genome-wide mapping of H3K4Me3 modification by ChIPseq. Firstly, we examined MYC and EGFR, two genes which are known to have high levels of H3K4Me3 in A549 cell. As shown in Figure 3(a), the degree of $\mathrm{H} 3 \mathrm{~K} 4 \mathrm{Me} 3$ at these genes significantly decreases following treatment with JFK. To further characterize these changes, a genome-wide peak detection analysis was performed using the MACS program. Compared to control, the $\mathrm{H} 3 \mathrm{~K} 4 \mathrm{Me} 3$ enrichment status at many TSSs in the JFK-treated cells was significantly altered (Table S1 in Supplementary Material available online at http://dx.doi.org/10.1155/2016/7276161). A heat map analysis of the top 2,000 genes showing altered levels of $\mathrm{H} 3 \mathrm{~K} 4 \mathrm{Me} 3$ $(P<0.05)$, including those exhibiting lower and greater levels of modification, identified promising candidates for further bioinformatic analysis (Figure 3(b)).

3.4. Gene Ontology Analysis of Genes with Altered H3K4Me3 Modification after JFK Treatment. We next analyzed the H3K4Me3 modification fold enrichment within 2,000 bp of TSSs between control- and JFK-treated A549 cells. We then identified the top 2,000 genes exhibiting altered levels of $\mathrm{H} 3 \mathrm{~K} 4 \mathrm{Me} 3(P<0.05)$ for further $\mathrm{GO}$ analysis and KEGG pathway analysis. The top ten GO terms are presented in Table 3. These results suggest that treatment with JFK could downregulate $\mathrm{H} 3 \mathrm{~K} 4 \mathrm{Me} 3$ modification levels at those genes involved in many pathways including ion transport, Wnt receptor signaling pathway, and positive regulation of transferase activity. By contrast, those genes with greater levels of $\mathrm{H} 3 \mathrm{~K} 4 \mathrm{Me} 3$ following JFK treatment are involved in programmed cell death, induction of apoptosis, positive regulation of $\mathrm{T}$ cell activation, and so forth.

KEGG pathway analysis suggests that the downregulated genes are enriched in pathways involved in pathways in cancer, basal cell carcinoma, pyrimidine metabolism, and so forth, whereas the upregulated genes are enriched in those pathways involved in tryptophan, apoptosis, base excision repair, and so forth (Figure $3(\mathrm{c})$ ). Network analysis of the top 50 downregulated GO terms in the JFK-treated A549 cells identified key signal transduction networks affected. As shown in Figure 4(a), three prominent GO terms associated with the downregulated genes include regulation of transcription (DNA-templated), intracellular signal transduction, and regulation of MAPK cascade. For top 50 upregulated GO terms, regulation of peptidase activity plays an important role in the whole network which can interact with induction of programmed cell death and apoptotic process indirectly (Figure 4(b)). Thus, overall, this Gene Ontology analysis suggests that JFK-induced apoptosis could be attributed to alteration in the levels of H3K4Me3 modification in many tumor-related genes. 

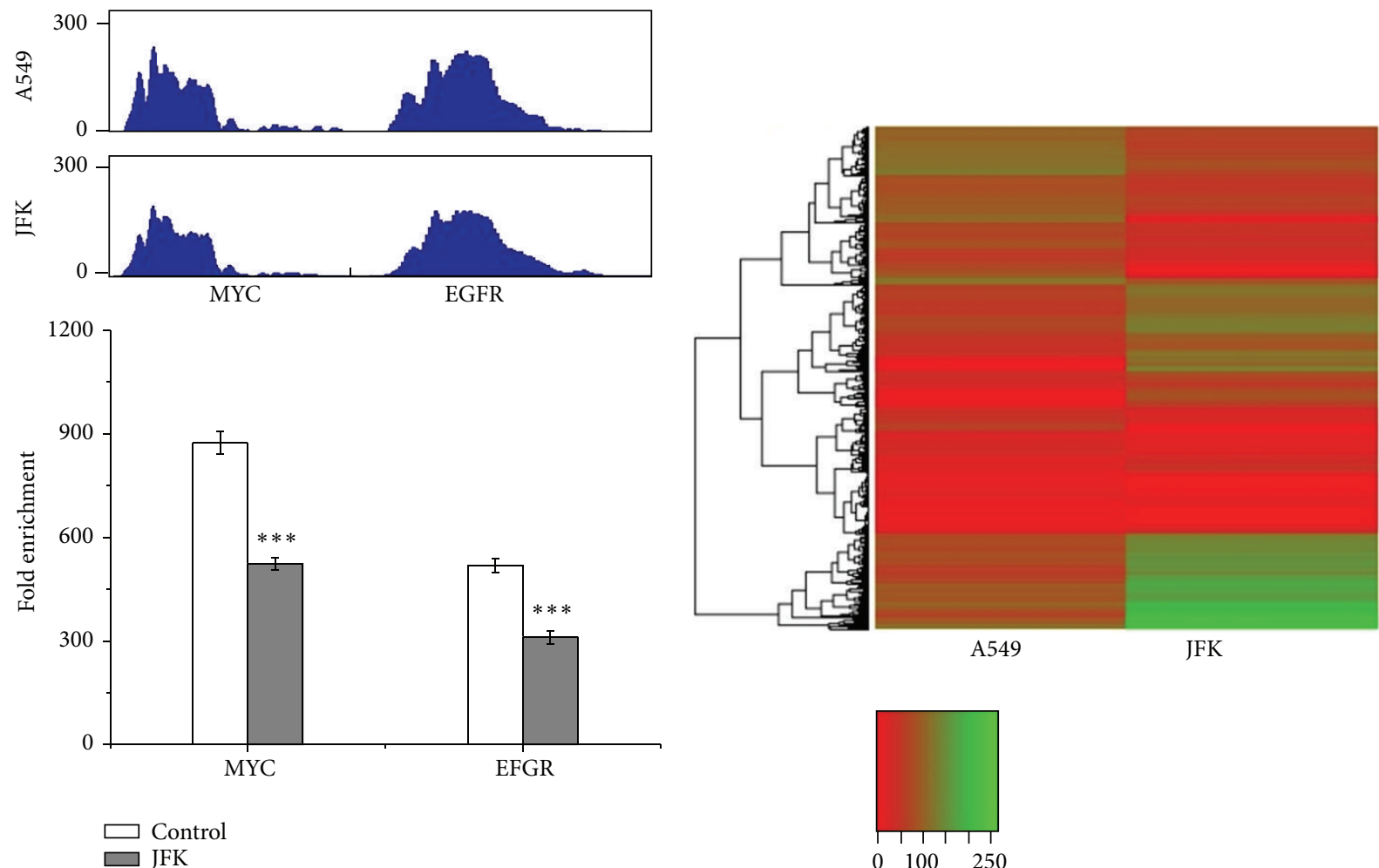

(a)

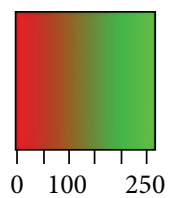

(b)

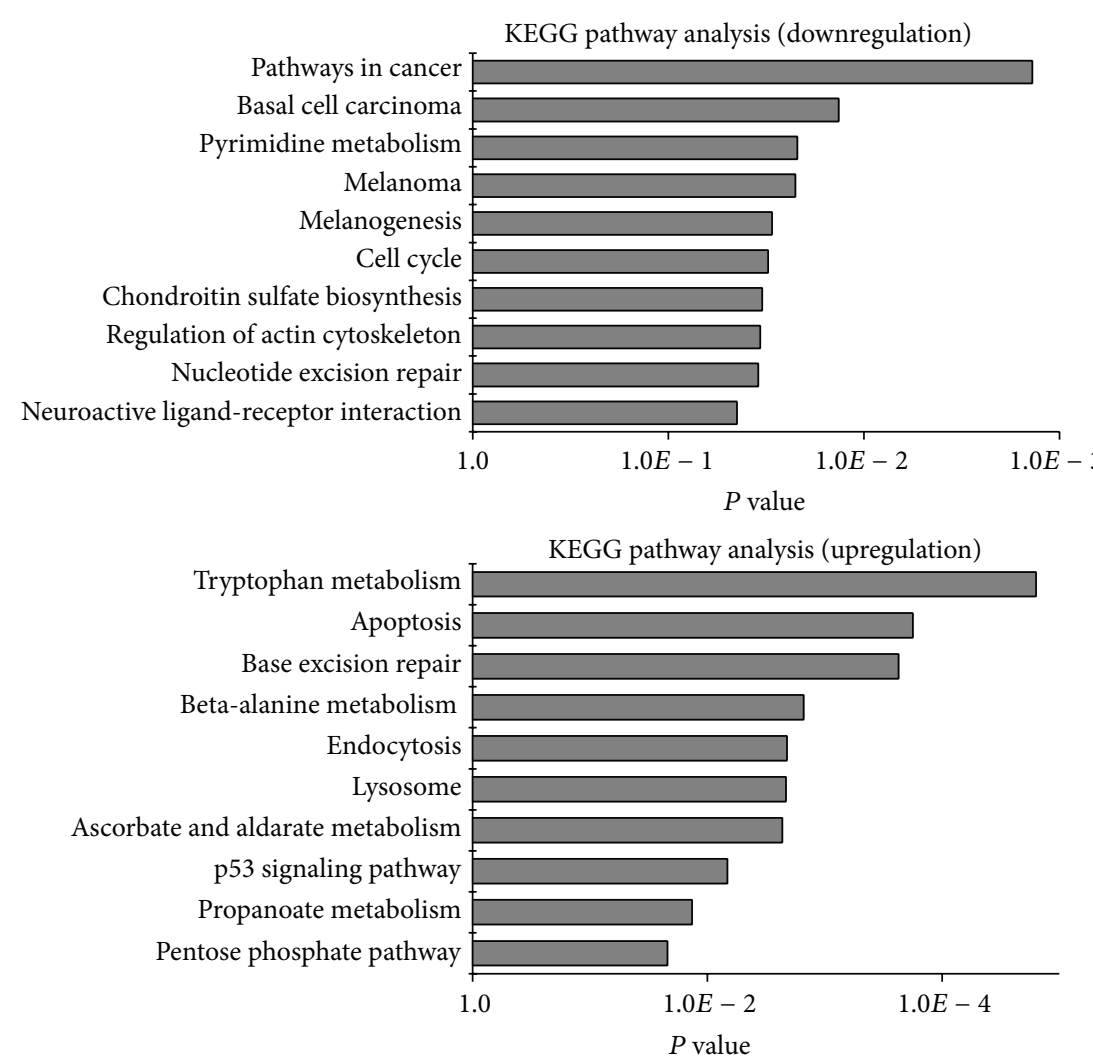

(c)

Figure 3: Gene Ontology analysis of JFK-induced A549 cell H3K4Me3 modification altered genes. (a) ChIP tag density profiles of H3K4Me3 modification at TSSs on MYC and EGFR genes. Fold change of MYC and EGFR H3K4Me3 modification status are detected by ChIP-qPCR $\left(n=4,{ }^{* * *} P<0.001\right)$. (b) Heat map of top 2000 H3K4Me3 modification altered genes from upregulation and downregulation, respectively, in A549 cells with or without JFK treatment $(P<0.05)$. (c) KEGG pathway analysis of upregulated and downregulated genes. 


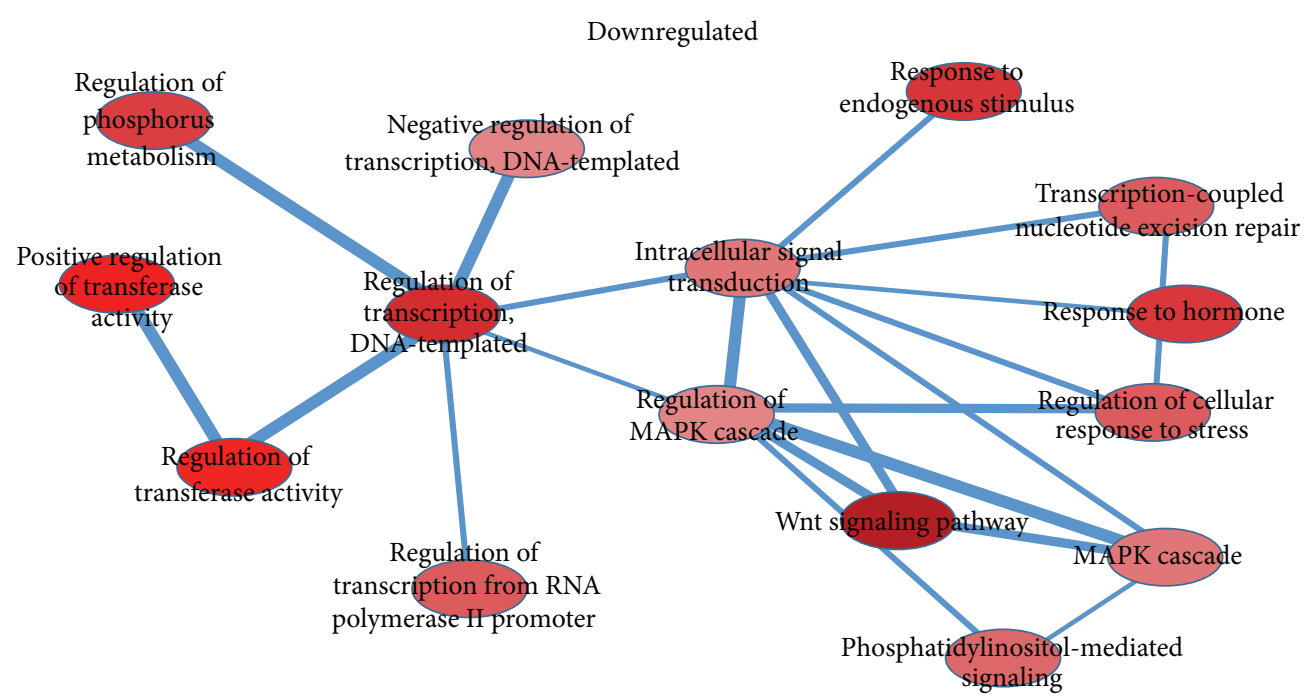

(a)

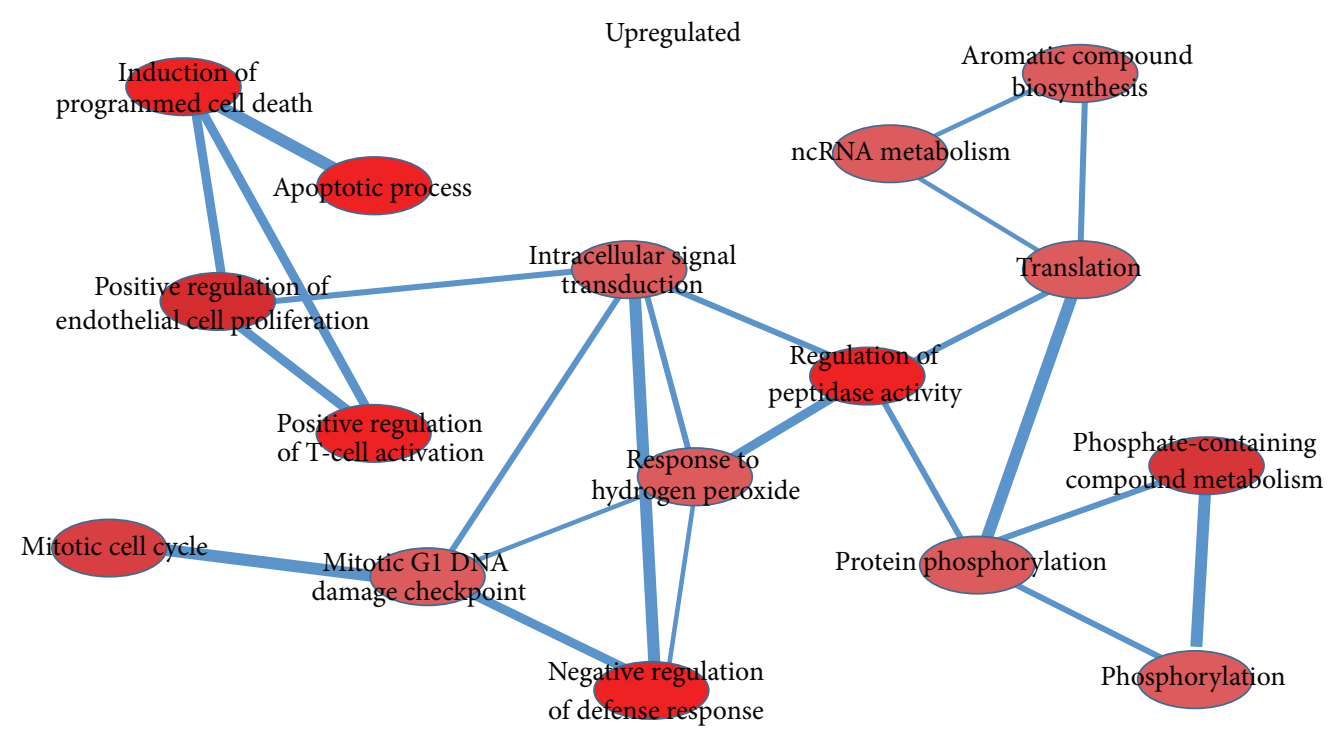

(b)

FIGURE 4: Network analysis of upregulated and downregulated genes. (a, b) Parts of top 50 GO terms from downregulated and upregulated genes, respectively, have mutual effect between each other. Degree of red color represents the $P$ value of GO terms (the lower $P$ value, the more red).

3.5. JFK Induces H3K4Me3 Alteration in Specific TumorRelated Genes in A549 Cells. To further understand the relationship between JFK-induced effects on A549 cell and changes in $\mathrm{H} 3 \mathrm{~K} 4 \mathrm{Me} 3$ levels at tumor-related genes, we analyzed the modification changes at five survival-regulated genes (SUSD2, PTN, GLIS2, CCND2, and TM4SF4) and five apoptosis-regulated genes (BCL2A1, IL31RA, WISP2, TNFAIP6, and TMEM158). As shown in Figure 5(a), treatment of A549 cells with JFK for $48 \mathrm{~h}$ downregulated the H3K4Me3 modification levels at SUSD2, PTN, GLIS2, CCND2, and TM4SF4 genes, whereas those at BCL2A1, IL31RA, WISP2, TNFAIP6, and TMEM158 genes were upregulated compared to those genes in control. The ChIP tag density profiles also matched these fold change results (Figure 5(b)). We also performed ChIP-qPCR to validate these high-throughput findings, and all genes, except GLIS2, showed similar changes (Figure 5(c)).

3.6. Verification of JFK-Induced H3K4Me3 Alteration in Other Lung Cancer Cell Lines. The above results suggest that JFKinduced A549 cell apoptosis could be due to changes in the $\mathrm{H} 3 \mathrm{~K} 4 \mathrm{Me} 3$ modification levels around the TSSs of some important genes. Therefore, we performed ChIP-qPCR to examine the $\mathrm{H} 3 \mathrm{~K} 4 \mathrm{Me} 3$ modification status of genes mentioned in the previous section in NCI-H1975, NCI-H1650, and NCI-H2228 cells treated with JFK for $48 \mathrm{~h}$. We found that the levels of $\mathrm{H} 3 \mathrm{~K} 4 \mathrm{Me} 3$ modification at SUSD2 and CCND2 are significantly decreased and those at BCL2A1 and TMEM158 are markedly increased in each of these cell lines 


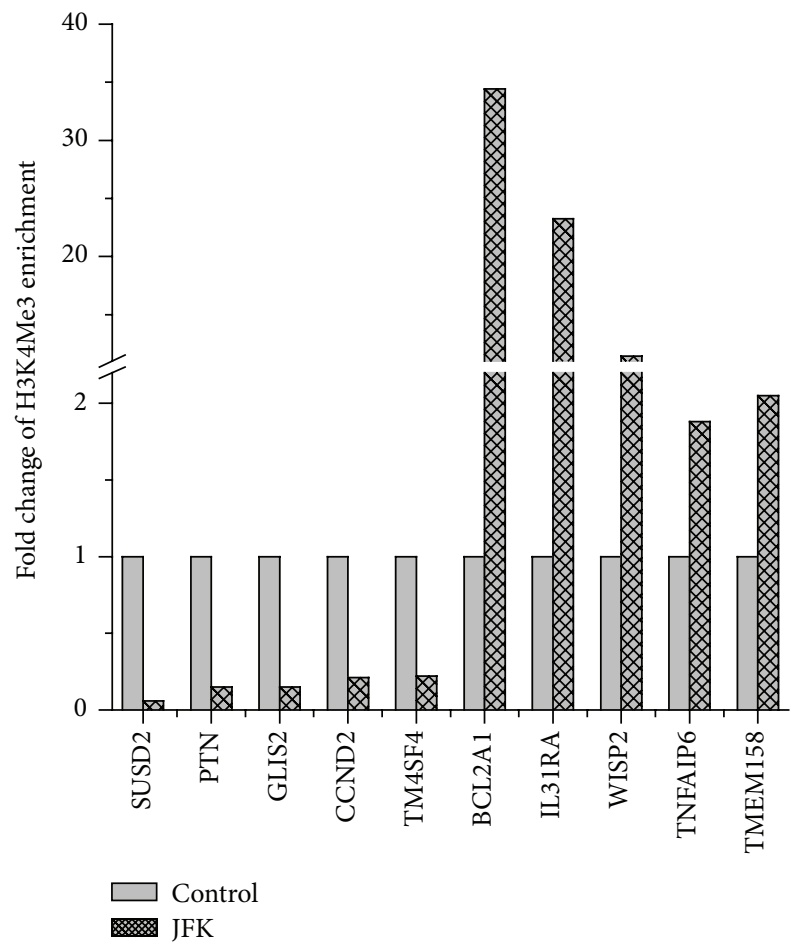

(a)
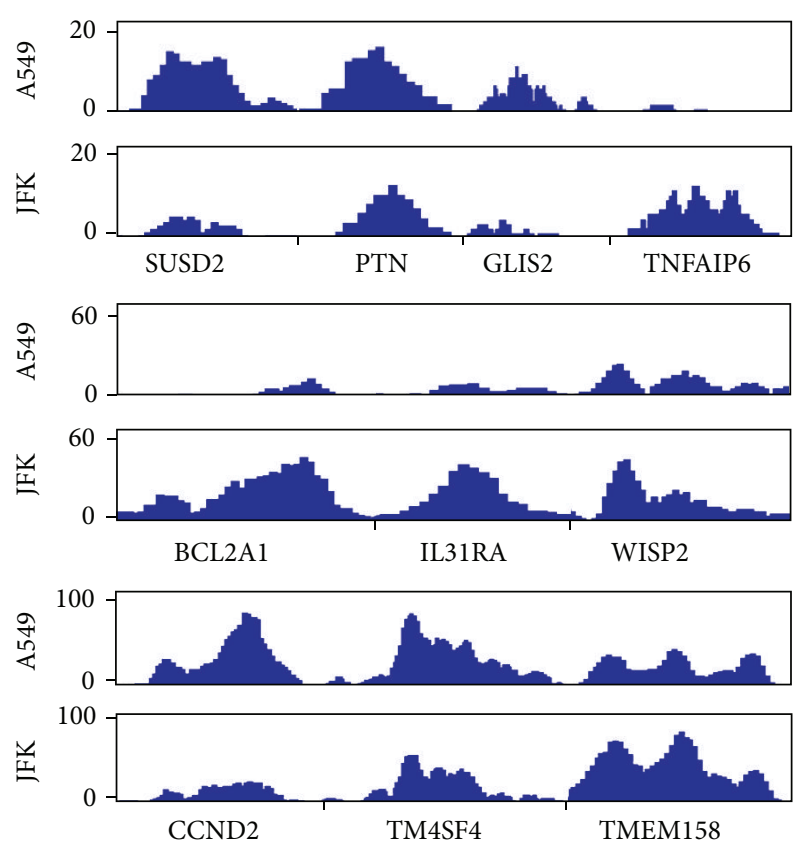

(b)

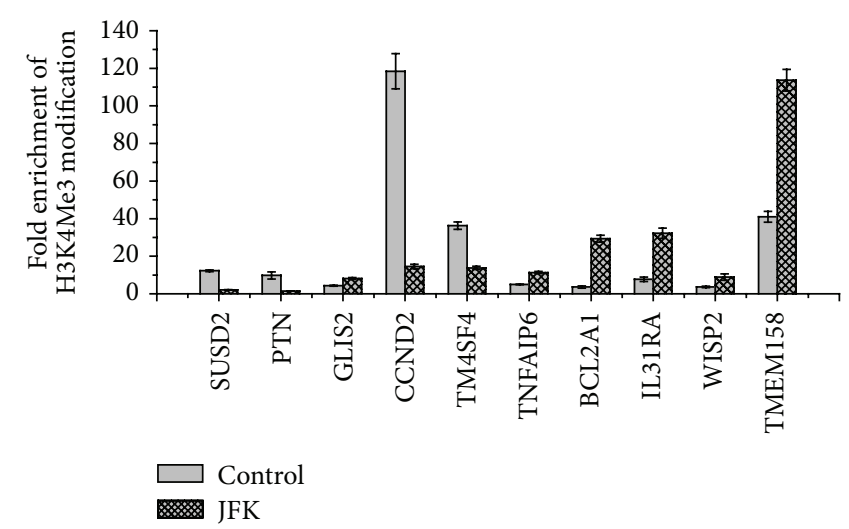

(c)

FIgURE 5: Analysis of H3K4Me3 pattern in the promoter regions of tumor-related genes after exposure to JFK. (a) Analysis of H3K4Me3 modification fold change in tumor-related genes based on ChIP-seq data. (b) ChIP tag density profiles of H3K4Me3 modification at TSSs on tumor-related genes. (c) Verification of H3K4Me3 modification altered genes using ChIP-qPCR $(n=3)$.

(Figures 6(a)-6(c)). Furthermore, an examination of the gene expression levels demonstrated that the levels of $\mathrm{H} 3 \mathrm{~K} 4 \mathrm{Me} 3$ modification are indeed positively correlated with the levels of gene expression (Figures 6(d) and 6(e)).

\section{Discussion}

The traditional Chinese medicine formula, JFK, had been used in clinical practice for treating human lung cancer patients for more than ten years [17]. Although the effectiveness of JFK has been well recognized by patients and physicians, the cellular and molecular mechanism remains unclear. Previous study demonstrated that JFK could modulate the expression of genes that are involved in the cell cycle and apoptosis [18]. Therefore, the objective of the present study was to understand the relationship between changes at the cellular level and changes in the degree of $\mathrm{H} 3 \mathrm{~K} 4 \mathrm{Me} 3$ modification and attempt to identify interesting gene targets that could play an important role in JFK-induced lung cancer cell apoptosis.

Previous studies have suggested that herbal formulas that suppress tumor growth and promote tumor cell apoptosis can be attributed to an inhibition of cell proliferation and activation of cell apoptosis $[16,26]$. Due to the complicated composition of herbal formulas, serum pharmacology of 


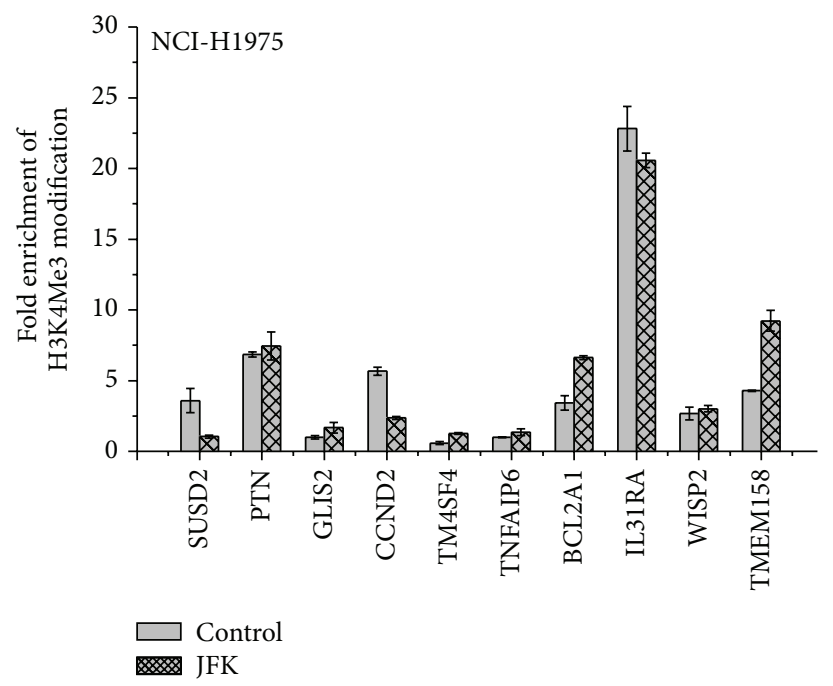

(a)

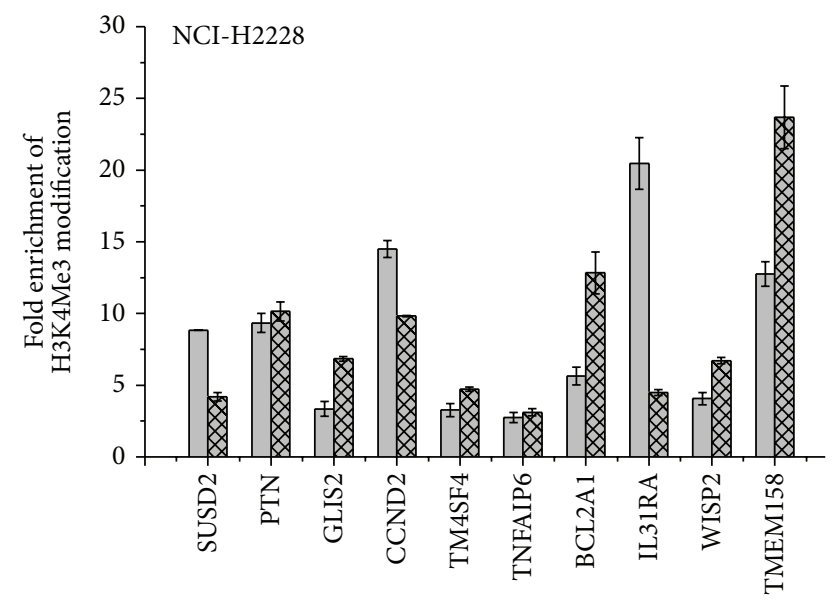

$\square$ Control JFK

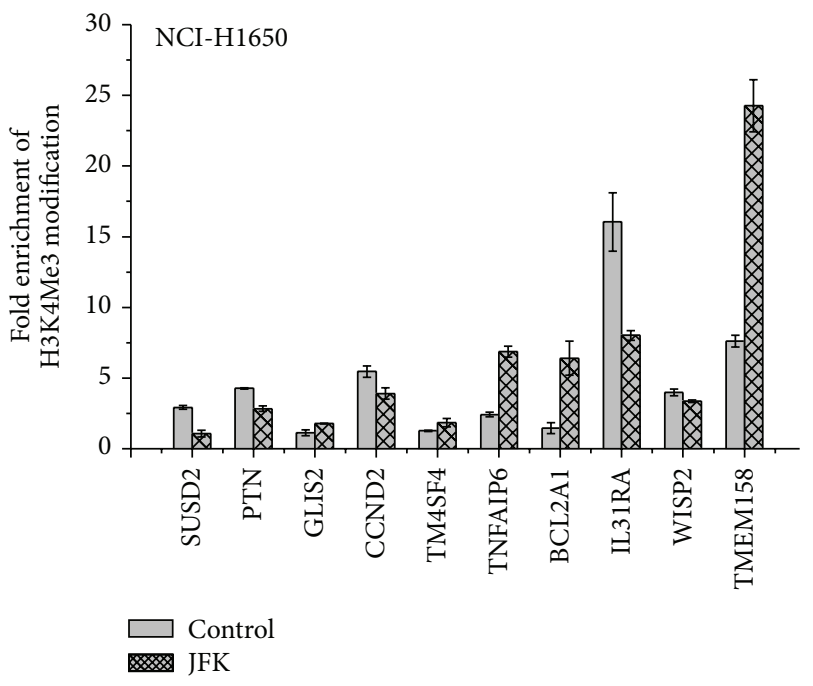

(b)

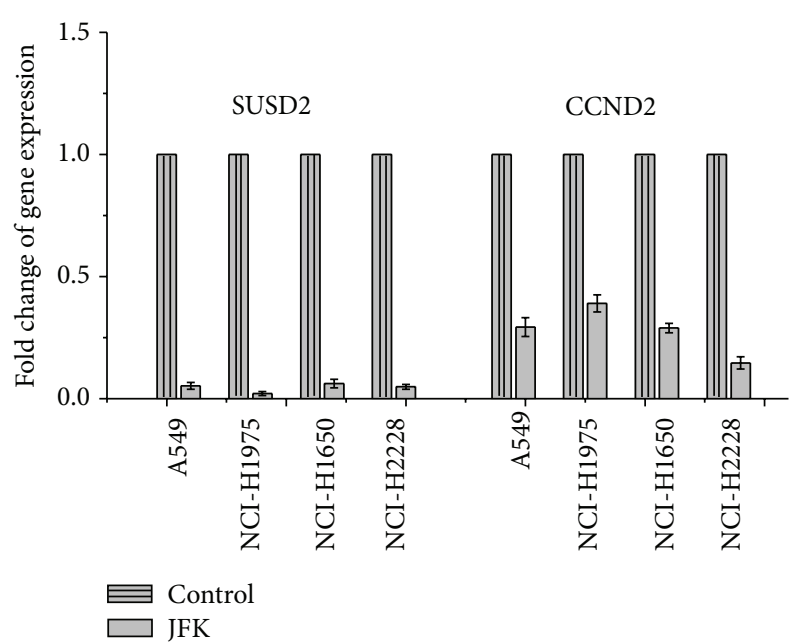

(d)

(c)

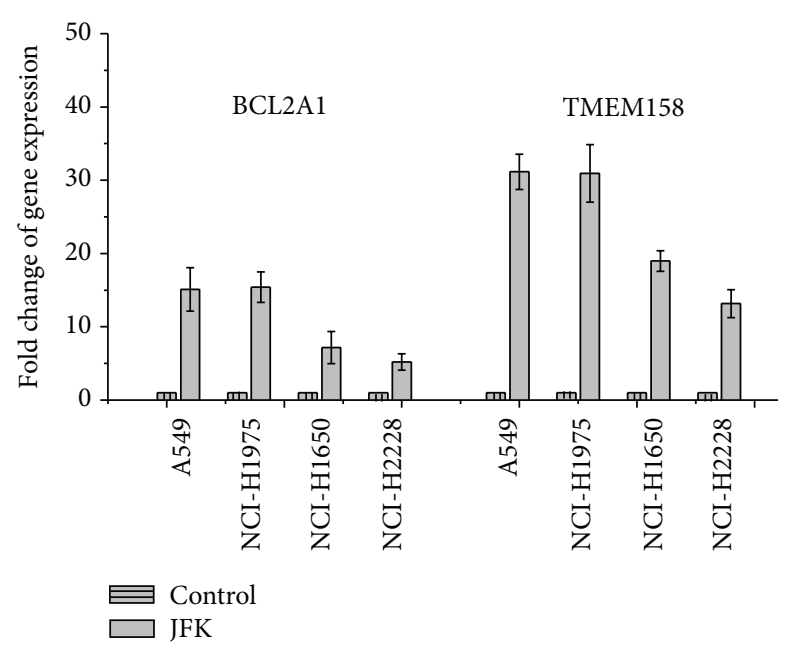

(e)

FIGURE 6: Analysis of JFK-induced H3K4Me3 pattern and mRNA levels alteration in human lung cancer cell lines. Cells were treated with JFK for $48 \mathrm{~h}$ and fold change of H3K4Me3 modification was detected by ChIP-qPCR $(n=3)$. (a) NCI-H1975 cell line. (b) NCI-H1650 cell line. (c) NCI-H2228 cell line. Cells were treated with JFK for $48 \mathrm{~h}$ and the mRNA levels of SUSD2, CCND2, BCL2A1, and TMEM158 were detected by RT-qPCR $(n=3)$. (d) Fold change of SUSD2 and CCND2 expression. (e) Fold change of BCL2A1 and TMEM158 expression. 
Traditional Chinese Medicine has been developed to understand the mechanism of TCM $[27,28]$. In this study, we examined the effects of JFK serums on cell growth and the cell nucleus in A549 cells. These results suggest that JFK lowered cell viability, inhibited cell growth, and altered cell nucleus morphology. Previous work has also demonstrated that tumor cells can be induced to death or apoptosis when they are exposed to formula extracts for fixed time [29, 30]. Our results suggest that many A549 cells are induced to death or apoptosis after exposure to JFK for $48 \mathrm{~h}$. Since the levels of $\mathrm{H} 3 \mathrm{~K} 4 \mathrm{Me} 3$ modification at promoter regions have been linked to disease development, therapy, and prognosis, we performed ChIP-qPCR assays to examine the levels of $\mathrm{H} 3 \mathrm{~K} 4 \mathrm{Me} 3$ modification at two oncogenes (MYC and EGFR) in control- and JFK-treated A549 cells, respectively. Previous studies found that there is a significant enrichment of $\mathrm{H} 3 \mathrm{~K} 4 \mathrm{Me} 3$ modification in the TSS regions of $M Y C$ and EGFR genes in many tumor cells $[31,32]$. Our results not only verified these earlier results in A549 cells, but also suggested that JFK can significantly reduce the levels of $\mathrm{H} 3 \mathrm{~K} 4 \mathrm{Me} 3$ modification at these genes.

$\mathrm{H} 3 \mathrm{~K} 4 \mathrm{Me} 3$ is an active histone modification, which can positively regulate gene expression $[3,6]$. Previous studies suggested that the levels of $\mathrm{H} 3 \mathrm{~K} 4 \mathrm{Me} 3$ modification of many genes can be altered after exposure to exogenous chemicals or metals $[33,34]$. Previous study revealed significant changes in gene expression and protein expression after JFK treatment [18]. However, the underlying epigenetic mechanism remained unclear. Here, we performed genome-wide mapping of $\mathrm{H} 3 \mathrm{~K} 4 \mathrm{Me} 3$ deposition in the promoter regions within $2000 \mathrm{bp}$ flanking the TSSs by ChIP-seq to enable characterization of the levels of $\mathrm{H} 3 \mathrm{~K} 4 \mathrm{Me} 3$ modification at nearly all genes with or without JFK treatment in A549 cells. We found that the genes with altered H3K4Me3 modification induced by JFK are enriched in multiple signal pathways. Tumor proliferation and apoptosis related signal pathways are known as important targets for many antitumor drugs [30]. Here, Gene Ontology analysis indicated that JFK-induced A549 cell proliferation inhibition and apoptosis promotion could be due to the alteration of levels of $\mathrm{H} 3 \mathrm{~K} 4 \mathrm{Me} 3$ modification on genes that belong to multiple tumor-related pathways including pathways in cancer, basal cell carcinoma, apoptosis, regulation of transcription (DNA-templated), and regulation of peptidase activity.

Previous study has suggested that SUSD2 interacts with galectin-1 (Gal-1), a $14 \mathrm{kDa}$ secreted protein that is synthesized by carcinoma cells and promotes tumor immune evasion, angiogenesis, and metastasis [35]. CCND2 is a cyclin whose function is to regulate the subunit of $C D K 4$ or $C D K 6$ and whose activity is required for cell cycle G1/S transition [36]. We found that the JFK-induced cell proliferation arrest could be owing to a reduction in the levels of $\mathrm{H} 3 \mathrm{~K} 4 \mathrm{Me} 3 \mathrm{mod}-$ ification at SUSD2 and CCND2 in A549 cells. BCL2A1 is wellknown antiapoptosis protein that converts into a proapoptotic protein when bound to NuBCP-9 [37]. TMEM158 is a transmembrane protein that is upregulated in response to activation of the Ras pathway and has been proposed to be a tumor-suppressor gene and a target gene in the mutator pathway [38]. The present study suggests that the increase in the $\mathrm{H} 3 \mathrm{~K} 4 \mathrm{Me} 3$ modification levels following JFK treatment at BCL2A1 and TMEM158 could explain JFK-induced A549 cell apoptosis. We note that, for other important genes, the significant changes in $\mathrm{H} 3 \mathrm{~K} 4 \mathrm{Me} 3$ modification observed in A549 cells after exposure to JFK for $48 \mathrm{~h}$ are not also found in NCI-H1975, NCI-H1650, and NCI-H2228 cell lines.

Taken together, this work presents the first report of JFK inducing proliferation inhibition and the promotion of apoptosis in A549 cells through a possible epigenetic mechanism and shows that JFK significantly altered the $\mathrm{H} 3 \mathrm{~K} 4 \mathrm{Me} 3$ histone modification levels at many genes that play critical roles in tumor survival related pathways. In particular, SUSD2, CCND2, BCL2A1, and TMEM158 could be potential targets of JFK in human lung cancers. Further studies are needed to assess the mechanism by which the changes in the levels of $\mathrm{H} 3 \mathrm{~K} 4 \mathrm{Me} 3$ modification at these genes lead to changes in gene or protein expression and eventually understand the utility of epigenetically altered genes as drug targets in the treatment of human lung cancers.

\section{Abbreviations \\ JFK: Jinfukang formula \\ TCM: Traditional Chinese medicine \\ ChIP-seq: Chromatin immunoprecipitation followed by high-throughput sequencing \\ TSS: Transcription start sites \\ CCK8: Cell Counting Kit 8 \\ DAPI: 4,6-Diamidino-2-phenylindole- \\ dihydrochloride \\ PI: $\quad$ Propidium iodide \\ DAVID: Database for Annotation, Visualization, and Integrated Discovery \\ GO: Gene Ontology \\ KEGG: Kyoto Encyclopedia of Genes and Genomes.}

\section{Competing Interests}

There are no competing interests.

\section{Authors' Contributions}

Ling Xu, Xiaodong Zhao, and Zhifeng Shao were involved in the conception and hypothesis delineation; Jun Lu, Xiaoli Zhang, and Tingting Shen performed the experiments, acquired the data, and analyzed the data; Jun $\mathrm{Wu}$ and Hualei Kong performed the ChIP-seq raw data analysis. Jing Tian and Xiaodong Zhao revised the paper; Chao Ma afforded help of theoretical basis on TCM; Jun Lu wrote the paper.

\section{Acknowledgments}

The authors thank Professor Daniel M. Czajkowsky for helpful discussion and careful proofreading. This work was supported by Longhua Medical Project of State Clinical Research Center of TCM in Longhua Hospital (LYTD-21 and JDZX2012123), National Basic Research Program of China 
(2013CB967402), and National Natural Science Foundation of China (81373623 and 91229123).

\section{References}

[1] M. A. Dawson and T. Kouzarides, "Cancer epigenetics: from mechanism to therapy," Cell, vol. 150, no. 1, pp. 12-27, 2012.

[2] M. A. Dawson, T. Kouzarides, and B. J. P. Huntly, "Targeting epigenetic readers in cancer," The New England Journal of Medicine, vol. 367, no. 7, pp. 647-657, 2012.

[3] T. Kouzarides, "Chromatin modifications and their function," Cell, vol. 128, no. 4, pp. 693-705, 2007.

[4] W. Fischle, Y. Wang, and C. D. Allis, "Histone and chromatin cross-talk," Current Opinion in Cell Biology, vol. 15, no. 2, pp. 172-183, 2003.

[5] P. Tessarz and T. Kouzarides, "Histone core modifications regulating nucleosome structure and dynamics," Nature Reviews Molecular Cell Biology, vol. 15, no. 11, pp. 703-708, 2014.

[6] B. A. Benayoun, E. A. Pollina, D. Ucar et al., "H3K4me3 breadth is linked to cell identity and transcriptional consistency," Cell, vol. 158, no. 3, pp. 673-688, 2014.

[7] R. G. Urdinguio, J. V. Sanchez-Mut, and M. Esteller, "Epigenetic mechanisms in neurological diseases: genes, syndromes, and therapies," The Lancet Neurology, vol. 8, no. 11, pp. 1056-1072, 2009.

[8] G. G. Wang, C. D. Allis, and P. Chi, "Chromatin remodeling and cancer. Part I. Covalent histone modifications," Trends in Molecular Medicine, vol. 13, no. 9, pp. 363-372, 2007.

[9] A. Mehta, S. Dobersch, A. J. Romero-Olmedo, and G. Barreto, "Epigenetics in lung cancer diagnosis and therapy," Cancer and Metastasis Reviews, vol. 34, no. 2, pp. 229-241, 2015.

[10] T. S. Furey, "ChIP-seq and beyond: new and improved methodologies to detect and characterize protein-DNA interactions," Nature Reviews Genetics, vol. 13, no. 12, pp. 840-852, 2012.

[11] C. Li and W. Hong, "Research status and funding trends of lung cancer biomarkers," Journal of Thoracic Disease, vol. 5, no. 5, pp. 698-705, 2013.

[12] Y. Namba, T. Kijima, S. Yokota et al., "Gefitinib in patients with brain metastases from non-small-cell lung cancer: review of 15 clinical cases," Clinical Lung Cancer, vol. 6, no. 2, pp. 123-128, 2004.

[13] R. Siegel, D. Naishadham, and A. Jemal, "Cancer statistics, 2013," CA: A Cancer Journal for Clinicians, vol. 63, no. 1, pp. 11-30, 2013.

[14] B. R. Cassileth, N. Rizvi, G. Deng et al., "Safety and pharmacokinetic trial of docetaxel plus an Astragalus-based herbal formula for non-small cell lung cancer patients," Cancer Chemotherapy and Pharmacology, vol. 65, no. 1, pp. 67-71, 2009.

[15] R. Ramesh, "Drug resistance in lung cancer," Lung Cancer: Targets and Therapy, vol. 1, pp. 23-36, 2010.

[16] R. Han, "Highlight on the studies of anticancer drugs derived from plants in China," STEM CELLS, vol. 12, no. 1, pp. 53-63, 1994.

[17] J. X. Liu, Z. M. Shi, H. G. Li et al., "Clinical observation on 271 cases of non-small cell lung cancer treated with Yifei Kangliu Yin," Chinese Journal of Integrated Traditional and Western Medicine, vol. 7, no. 4, pp. 247-250, 2001.

[18] S. J. Liu and J. L. Sun, 'Effect of 'Jinfukang oral solution' on expression of apoptosis related genes of human lung adenocarcinoma cells transplanted in nude mice," Shanghai Journal of Traditional Chinese Medicine, no. 10, pp. 69-71, 2007.
[19] L. Jiao, Y. Wang, L. Xu, and M. You, "Lung cancer prevention and therapy using the JinFuKang herbal mixture," Current Pharmacology Reports, vol. 1, no. 5, pp. 346-353, 2015.

[20] Y.-R. Jiang, Y. Miao, L. Yang et al., "Effect of chinese herbal drug-containing serum for activating-blood and dispellingtoxin on ox-LDL-induced inflammatory factors' expression in endothelial cells," Chinese Journal of Integrative Medicine, vol. 18, no. 1, pp. 30-33, 2012.

[21] B. Langmead and S. L. Salzberg, "Fast gapped-read alignment with Bowtie 2," Nature Methods, vol. 9, no. 4, pp. 357-359, 2012.

[22] Y. Zhang, T. Liu, C. A. Meyer et al., "Model-based analysis of ChIP-Seq (MACS)," Genome Biology, vol. 9, no. 9, article R137, 2008.

[23] G. Dennis Jr., B. T. Sherman, D. A. Hosack et al., "DAVID: database for annotation, visualization, and integrated discovery," Genome Biology, vol. 4, no. 5, p. P3, 2003.

[24] D. W. Huang, B. T. Sherman, and R. A. Lempicki, "Systematic and integrative analysis of large gene lists using DAVID bioinformatics resources," Nature Protocols, vol. 4, no. 1, pp. 44-57, 2008.

[25] M. Kanehisa and S. Goto, "KEGG: kyoto encyclopedia of genes and genomes," Nucleic Acids Research, vol. 28, no. 1, pp. 27-30, 2000.

[26] M. Li-Weber, "Targeting apoptosis pathways in cancer by Chinese medicine," Cancer Letters, vol. 332, no. 2, pp. 304-312, 2013.

[27] X. Huang, L. Kong, X. Li, X. Chen, M. Guo, and H. Zou, "Strategy for analysis and screening of bioactive compounds in traditional Chinese medicines," Journal of Chromatography B: Analytical Technologies in the Biomedical and Life Sciences, vol. 812, no. 1-2, pp. 71-84, 2004.

[28] W. Bochu, Z. Liancai, and C. Qi, "Primary study on the application of Serum Pharmacology in Chinese traditional medicine," Colloids and Surfaces B: Biointerfaces, vol. 43, no. 3-4, pp. 194-197, 2005.

[29] L.-D. Guo, X.-J. Chen, Y.-H. Hu, Z.-J. Yu, D. Wang, and J.-Z. Liu, "Curcumin inhibits proliferation and induces apoptosis of human colorectal cancer cells by activating the mitochondria apoptotic pathway," Phytotherapy Research, vol. 27, no. 3, pp. 422-430, 2013.

[30] J. Gao, W. A. Morgan, A. Sanchez-Medina, and O. Corcoran, "The ethanol extract of Scutellaria baicalensis and the active compounds induce cell cycle arrest and apoptosis including upregulation of p53 and Bax in human lung cancer cells," Toxicology and Applied Pharmacology, vol. 254, no. 3, pp. 221228, 2011.

[31] C. Y. Lin, J. Lovén, P. B. Rahl et al., "Transcriptional amplification in tumor cells with elevated c-Myc," Cell, vol. 151, no. 1, pp. 56-67, 2012.

[32] P. Erfani, J. T. Garcia, P. Canoll, and N. Tsankova, "Abstract 3831: Ash2L and p300 mediate histone H3 modifications at EGFR during its developmental silencing and re-expression in gliomas," Cancer Research, vol. 75, no. 15, supplement, p. 3831, 2015.

[33] K.-M. Tchou-Wong, K. Kiok, Z. Tang et al., "Effects of nickel treatment on $\mathrm{H} 3 \mathrm{~K} 4$ trimethylation and gene expression," PLoS ONE, vol. 6, no. 3, Article ID el7728, 2011.

[34] J. Zhang, Y.-L. Chen, G. Ji et al., "Sorafenib inhibits epithelialmesenchymal transition through an epigenetic-based mechanism in human lung epithelial cells," PLoS ONE, vol. 8, no. 5, Article ID e64954, 2013. 
[35] A. P. Watson, R. L. Evans, and K. A. Egland, "Multiple functions of sushi domain containing 2 (SUSD2) in breast tumorigenesis," Molecular Cancer Research, vol. 11, no. 1, pp. 74-85, 2013.

[36] M. Meyerson and E. Harlow, "Identification of G1 kinase activity for cdk6, a novel cyclin D partner," Molecular and Cellular Biology, vol. 14, no. 3, pp. 2077-2086, 1994.

[37] M. Vogler, "BCL2A1: the underdog in the BCL2 family," Cell Death and Differentiation, vol. 19, no. 1, pp. 67-74, 2012.

[38] A. E. S. Mohammed, H. Eguchi, S. Wada et al., "TMEM158 and FBLP1 as novel marker genes of cisplatin sensitivity in nonsmall cell lung cancer cells," Experimental Lung Research, vol. 38, no. 9-10, pp. 463-474, 2012. 


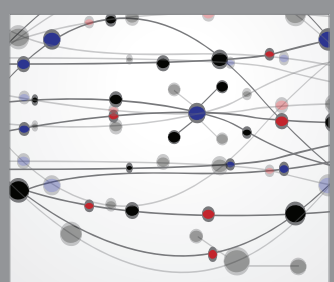

The Scientific World Journal
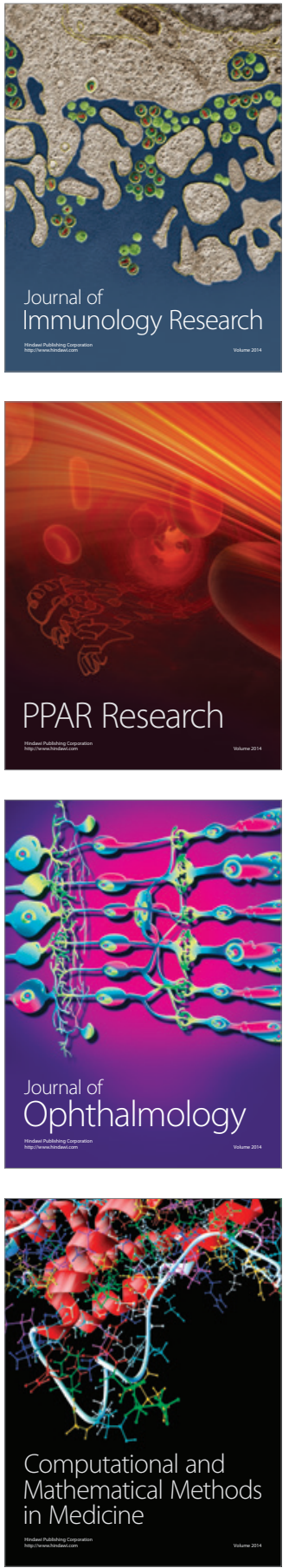

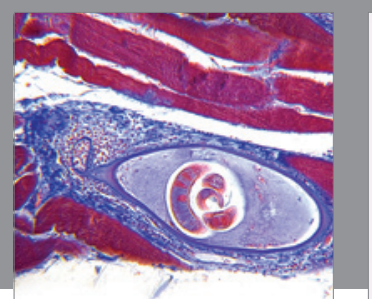

Gastroenterology Research and Practice

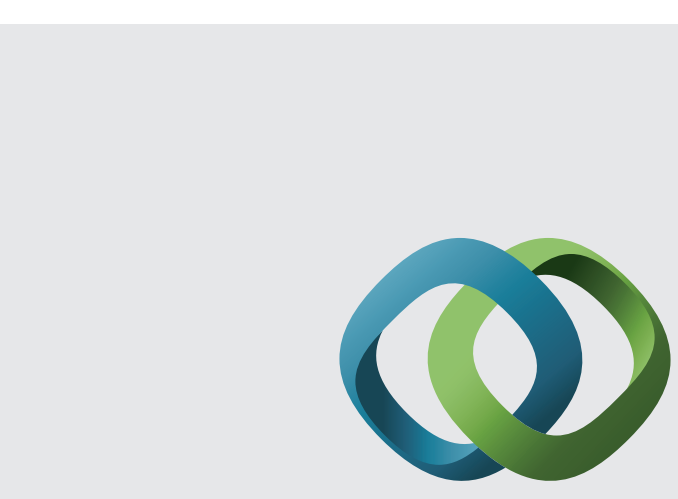

\section{Hindawi}

Submit your manuscripts at

http://www.hindawi.com
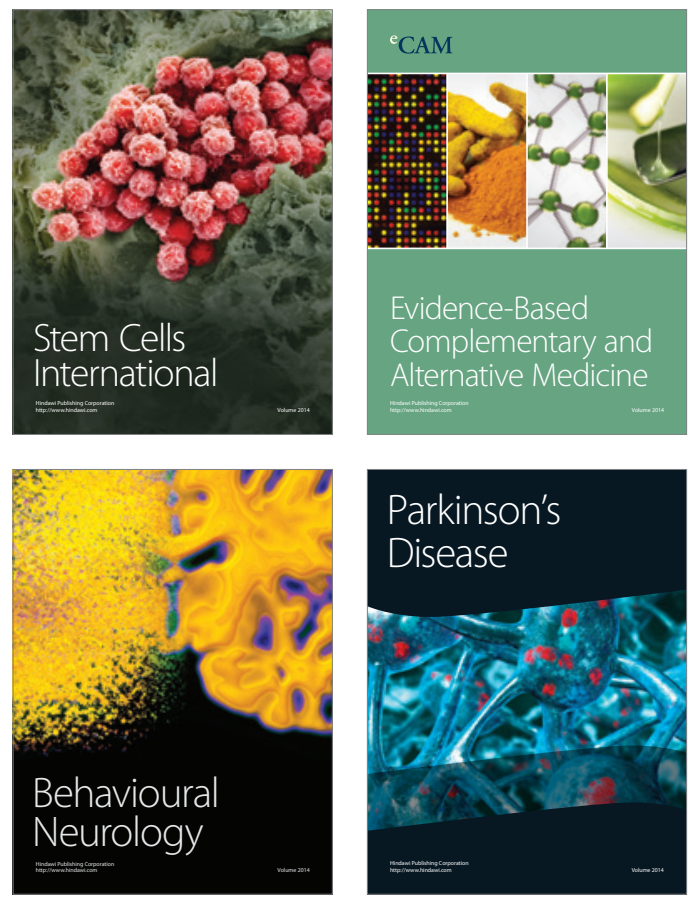
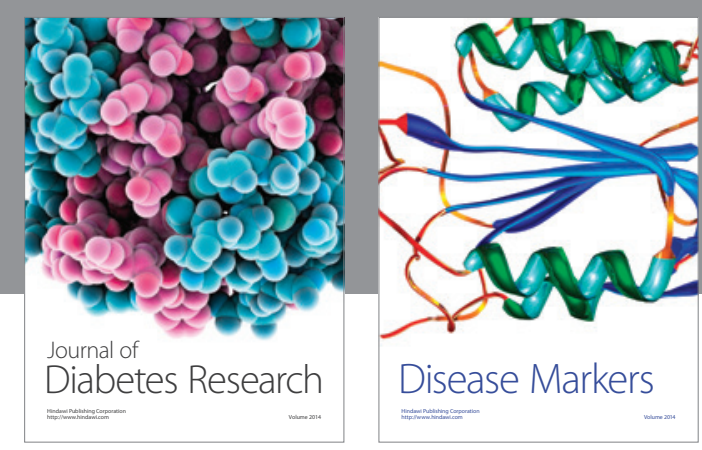

Disease Markers
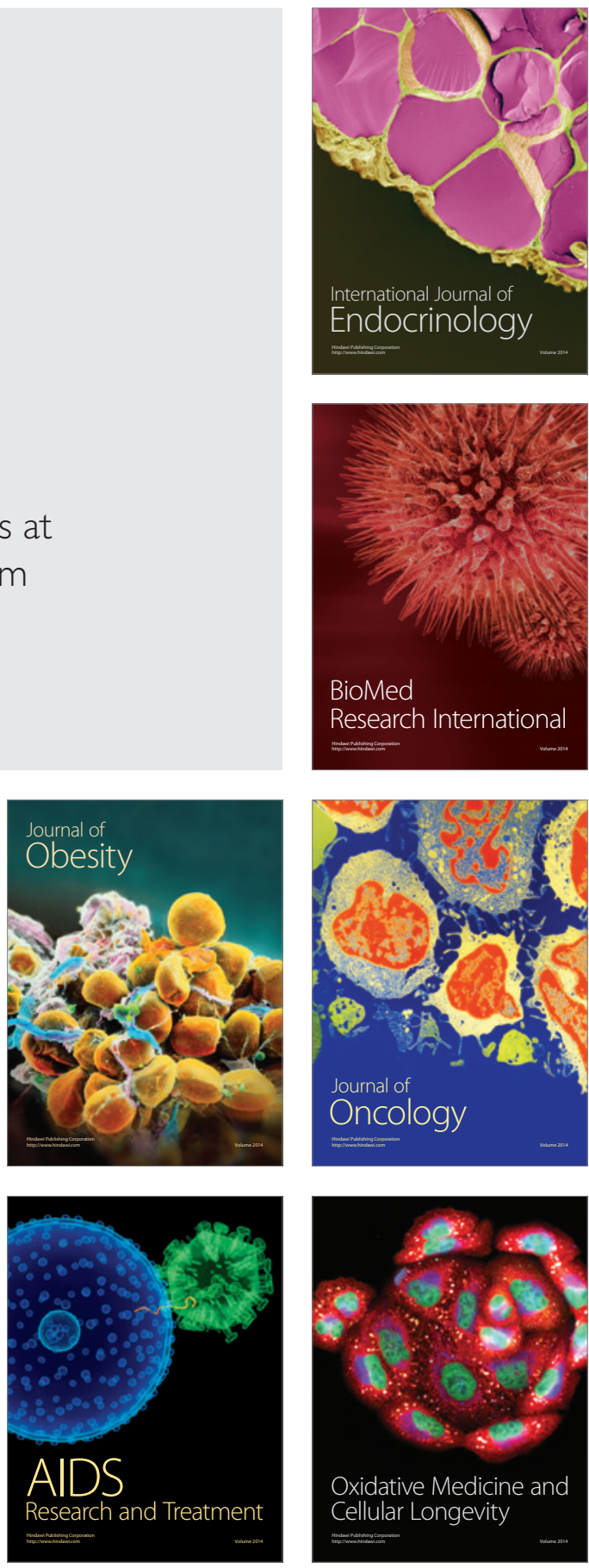